\title{
QRS Vector Magnitude as Predictor of Ventricular Arrhythmia in Patients With Brugada Syndrome
}

\author{
Ahmed A.Y. Ragab, MBBCh, Charlotte A. Houck, MD, Lisette J.M.E. van der Does, MD, \\ Eva A.H. Lanters, MD, Agnes J.Q.M. Muskens, RN, and Natasja M.S. de Groot, MD, PhD*
}

\begin{abstract}
Risk stratification is the most challenging part in management of patients with Brugada syndrome (BrS). Conduction delay in the right ventricular outflow tract (RVOT) is the major mechanism underlying ventricular tachyarrhythmia (VTA) in BrS. However, QRS duration was not useful in stratifying high-risk patients in large registries. Reconstructing the traditional 12-lead electrocardiogram into QRS vector magnitude can be used to quantify depolarization dispersion and identify high-risk $\mathrm{BrS}$ patients. The aim of the study is to test the significance of the QRSvm as a predictor for VTA in patients with BrS. In this retrospective cohort, we included 136 patients $(47 \pm 15$ years, $66 \%$ male) who visited outpatient clinic for cardiogenetic screening. All medical records were examined, all 12- lead electrocardiograms were reconstructed into QRSvm using Kors' quasiorthogonal method and were assessed for the presence of electrocardiographic signs indicative of RVOT conduction delay including $R$ wave sign, deep SI, SII > SIII pattern, and Tzou criteria. QRSvm was significantly lower in patients who either presented with VTA or developed VTA during follow-up $(1.24 \pm 0.35$ vs $1.78 \pm 0.42 \mathrm{mV}, \mathrm{p}<0.001)$. Positive RVOT conduction delay signs occurred more frequently in symptomatic patients $(20 \% \mathrm{vs} 7 \%$, $\mathrm{p}<\mathbf{0 . 0 0 1}$ ). The area under receiver operator characteristic curve for QRSvm was 0.85 (95\% confidence interval [CI] 0.77 to 0.92 ). Using QRSvm cutoff of $1.55 \mathrm{mV}$, sensitivity and specificity were $89 \%$ and $71 \%$, respectively. Multivariate regression analysis showed that QRSvm and RVOT signs are independent predictors for VTA in BrS patients (QRS vector magnitude: odds ratio 3.68, 95\% CI 2.4 to $6.2, \mathrm{p}=\mathbf{0 . 0 0 1}$; RVOT: odds ratio $2.6,95 \%$ CI 1.4 to $4.9, p=0.001$ ). In conclusion, not only electrocardiographic signs indicative of RVOT conduction delay but also QRSvm can be used as a predictor for VTA events in BrS patients. @ 2019 Elsevier Inc. All rights reserved. (Am J Cardiol 2019;123:1962-1966)
\end{abstract}

Brugada syndrome $(\mathrm{BrS})$ is an autosomal dominant channelopathy characterized by an increased risk of sudden cardiac death in young subjects without structural anomalies. ${ }^{1}$ This channelopathy has an incidence of $0.05 \%$ to $0.6 \%$ in the general population and can be diagnosed by ST-segment elevation in the right precordial leads either spontaneously or after provocation test using sodium channel blockers. ${ }^{2}$ Stratifying the high-risk patients is the most challenging part of BrS management. Many investigators reported on testing different electrocardiographic parameters to quantify the risk of ventricular tachyarrhythmia (VTA) especially in asymptomatic patients. The controversial outcomes make this task unfortunately very challenging. ${ }^{3-5}$ However, there is a strong evidence that conduction delay in right ventricular outflow tract (RVOT) is the main mechanism underlying VTA in BrS yet, time parameters such as QRS duration did not have strong prognostic value in large registries. ${ }^{6,7}$ Voltage-dependent vectorcardiographic parameters have proved to add diagnostic and prognostic value to the 12-lead surface electrocardiogram (ECG). ${ }^{8-10}$ Voltage-dependent QRS 3-dimensional vector magnitude

Department of Cardiology, Erasmus University Medical Center, Rotterdam, the Netherlands. Manuscript received January 25, 2019; revised manuscript received and accepted March 14, 2019.

See page 1965 for disclosure information.

*Corresponding author: Tel: +31-10-7035018; fax: +31-10-7035258.

E-mail address: n.m.s.degroot@erasmusmc.nl (N.M.S. de Groot).
(QRSvm) is a promising parameter for predicting VTA in patients with tetralogy of Fallot (TOF). ${ }^{11,12}$ Lower QRSvm indicates scattering of slowly propagating electrical waves, resulting in dispersion of depolarization vectors. As a consequence, the QRS magnitude decreases. In this study, we tested if QRSvm can be a useful predictor for VTA including VT and VF during long-term follow-up.

\section{Methods}

This blinded retrospective study is part of the "EvaluatioN of CardiOgenetic Disease and Effectiveness of scReening" (ENCODER) project, which was approved by the local ethics committee in the Erasmus Medical Center Rotterdam, the Netherlands (MEC-2014-313). Informed consent was not required. All data, including clinical characteristics and tests outcomes, were collected from digital medical records. During the follow-up period, all patients visited the cardiology outpatient clinic at least once a year and implantable cardioverter defibrillator (ICD) were checked twice a year. ECGs, Holter recordings signal-averaged electrocardiograms (SAECG) and ICD print outs were reviewed for the occurrence of VTA or ICD shocks. Patients were excluded when data regarding the diagnostic process (i.e., test outcomes and patient or family history) were missing.

We selected patients' definitive BrS diagnosis from the database of patients with suspicion of cardiac channelopathies visiting the outpatient clinic for cardiogenetic evaluation in 


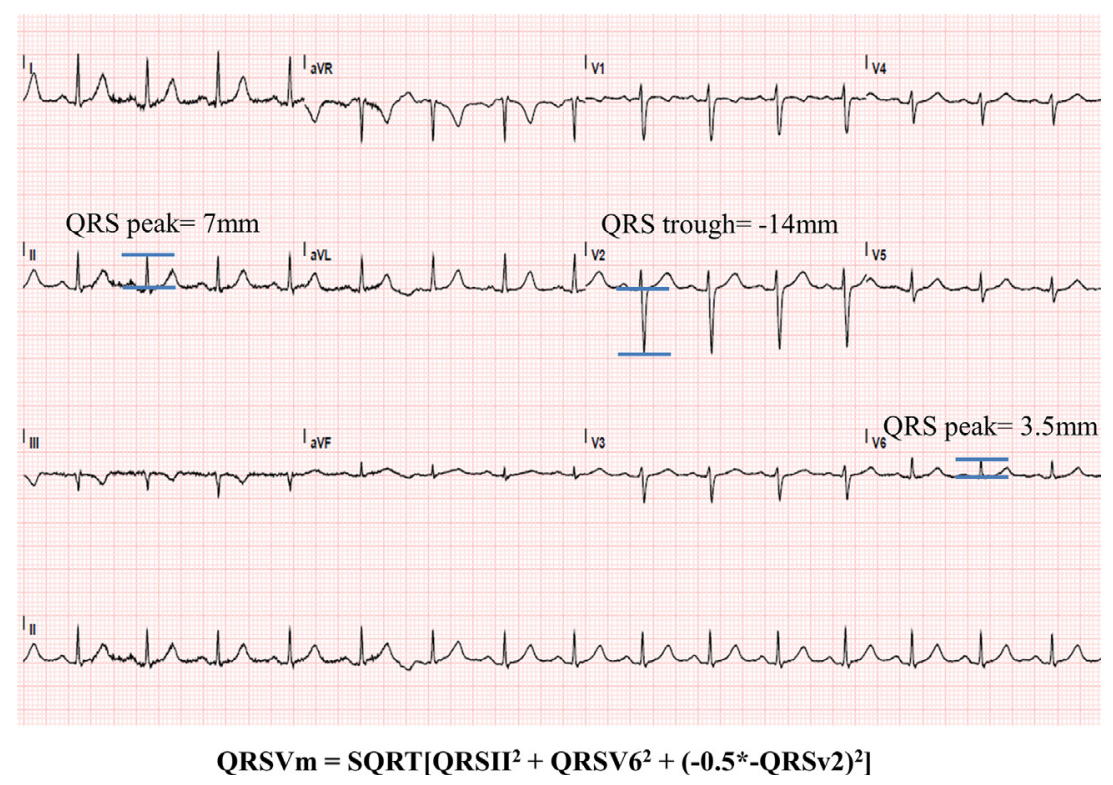

Figure 1. Baseline electrocardiogram of an Ajmaline-induced BrS patient demonstrating measurement of QRSvm.

the Erasmus Medical Center Rotterdam, the Netherlands. According to the criteria defined in the latest consensus report, diagnosis of type I $\mathrm{BrS}$ was based on the presence of either spontaneous or sodium channel blockers induced type I morphology (coved pattern) ST segment elevation $\geq 2 \mathrm{~mm}$ in 1 or more of the right precordial leads V1 to V3. Type II diagnosis was defined as conversion of type II morphology ST segment elevation into type I morphology after drug challenge test in 1 or more lead among the right precordial leads V1 to V3. ${ }^{2}$ Patients with obesity (body mass index $>29.9$ ), Chronic Obstructive Pulmonary Disease (COPD), or BrS patients who developed ischemic heart disease were excluded.

RVOT conduction delay signs were tested, including the $\mathrm{R}$ wave sign, deep SI, SII $>$ SIII pattern, Tzou criteria (V1R $>0.15 \mathrm{mV}, \mathrm{V} 6 \mathrm{~S}>0.15 \mathrm{mV}$; and V6S:R $>0.2) .{ }^{13-15}$ Patients with 3 or more positive signs were considered as positive for RVOT conduction delay; QRS durations were measured in lead aVR.

Figure 1 demonstrated determination of the QRS vector magnitude (QRSvm). This parameter was tested in all ECGs using the regression-related Frank-lead technique of Kors. ${ }^{16}$ The following formula was used for QRSvm estimation:

$\sqrt{\left.\left\{(\mathrm{QRS} \text { peak lead II })^{2}+(\mathrm{QRS} \text { peak lead V6 })^{2}+(-0.5 *-\mathrm{QRS} \text { trough lead V2 })^{2}\right\}\right)}$

All peaks were measured manually from digital ECGs (25 mm/s; $10 \mathrm{~mm} / \mathrm{mV})$.

Continuous normally distributed variables were expressed as mean \pm standard deviation. Continuous not normally distributed variables were expressed as median and interquartile range. Independent samples $t$ test were used to compare patient groups. Categorical data were denoted by percentages and compared with continuity correction chi-squared test. Receiver operator characteristic curves were used to estimate the optimal cutoff and to evaluate sensitivity and specificity of tested parameters. The multivariable regression model was used to assess the relation between development of
VTA and independent variables including the different electrocardiographic parameters ( $\mathrm{R}$ wave sign, deep SI, SII $>$ SIII pattern, Tzou criteria; V1R $>0.15 \mathrm{mV}$, V6S $>0.15 \mathrm{mV}$, and V6S:R $>0.2$ ) A p value of $<0.05$ was considered statistically significant. Statistical analysis was performed with SPSS version 21 (IBM, Armonk, New York).

\section{Results}

The study population consists of $136 \mathrm{BrS}$ patients (90 male, 66\%); characteristics are summarized in Table 1. Mean age at the time of diagnosis was $47 \pm 15$ years. The median duration of the follow-up period was 57 (interquartile range 39 to 75) months and mean age at the time of the last follow-up was $47 \pm 15$ years. Whole genome sequencing was done in 43 patients $(32 \%)$ and $8(6 \%)$ of them had SCN5A mutation. An ICD was implanted in 34 patients (25\%) either for primary $(\mathrm{n}=14,14$ of $136,10 \%)$ or secondary prevention $(\mathrm{n}=20,20$ of $136,15 \%)$.

Most patients $(\mathrm{n}=101,74 \%)$ remained asymptomatic during the follow-up period. Thirty-five patients developed VTA either before diagnosis $(\mathrm{n}=22,16 \%)$ or de novo

Table 1

Baseline characteristics of study population

\begin{tabular}{lc}
\hline & $\begin{array}{c}\text { Overall population } \\
(\mathrm{n}=136)\end{array}$ \\
\hline Age (years) & $47 \pm 15$ \\
Males & $90(66 \%)$ \\
Age of diagnosis (years) & $42 \pm 14$ \\
Symptoms at the moment of diagnosis & $22(16 \%)$ \\
De novo VTA events during follow-up & $13(10 \%)$ \\
SCN5A mutation & $8 / 43$ \\
Implantable cardioverter defibrillator & $34(25)$ \\
VT/VF ICD shocks & $8(5 \%)$ \\
Inappropriate ICD shocks & $10(7 \%)$ \\
Positive late potentials & $56(41 \%)$ \\
\hline
\end{tabular}


events during follow-up $(\mathrm{n}=13,10 \%)$. During the followup period, 8 patients $(5 \%)$ received appropriate ICD shocks and 10 patients $(7 \%)$ received inappropriate ICD shocks caused by supraventricular arrhythmia. Six patients used Quinidine and none of them developed VTA (Table 1). Fifty-one patients (38\%) underwent electrophysiological study and VT/VF was inducible in 7 patients (5\%). The SA-ECG was positive for late potentials in 56 patients $(41 \%)$.

There were no differences between symptomatic and asymptomatic patients with respect to age, gender, or age of diagnosis. Also, mean QRS duration in lead aVR and late potentials did not differ between symptomatic and asymptomatic patients (respectively, $113 \pm 17$ vs $117 \pm$ $17 \mathrm{~ms}, \mathrm{p}=0.26$ and 10 of $35,29 \%$ vs 46 of $101,46 \%, \mathrm{p}=$ 0.07).

Positive RVOT signs ( 3 or more) appeared in 25 patients (18\%), RVOT signs were more frequently observed among symptomatic patients $(54 \%$ vs $6 \%, \mathrm{p}<0.001)$.

By comparing QRS peak in lead II, QRS peak in lead V6 and QRS trough in lead V2, symptomatic patients showed smaller QRS peak or trough than asymptomatic patients (QRS II: $8 \pm 3$ vs $12 \pm 4 \mathrm{~mm}, \mathrm{p}<0.001$; QRS V6: $8 \pm 3$ vs $11 \pm 3 \mathrm{~mm}, \mathrm{p}<0.001$; QRS V2: $9 \pm 4$ vs $12 \pm 4 \mathrm{~mm}$, $\mathrm{p}<0.001$; Table 2). As demonstrated in Figure 2, QRSvm was significantly lower in patients who developed VTA (at the time of presentation or de novo) than patients who did not $(1.24 \pm 0.35$ vs $1.78 \pm 0.42 \mathrm{mV}, \mathrm{p}<0.001)$.

Area under receiver operator characteristic curve for QRSvm was 0.85 (95\% confidence interval [CI] 0.77 to 0.92; Figure 3). Using QRSvm cutoff of $1.55 \mathrm{mV}$, sensitivity and specificity were, respectively, $89 \%$ and $71 \%$. Area under receiver operator characteristic for RVOT was 0.74 ( $95 \%$ CI 0.633 to 0.85 ) with a sensitivity of $54 \%$ and specificity of $94 \%$.

In multivariable regression analysis, both QRSvm and positive RVOT signs are independent predictors for VTA events in BrS. Patients with lower QRSmv had fourfold higher risk to develop VTA (odds ratio [OR] 3.68, 95\% CI 2.4 to $6.2, p=0.001$ ), whereas patients with positive RVOT signs had threefold higher risk (OR 2.6, 95\% CI 1.4 to 4.9, $\mathrm{p}=0.001$ ).

Table 2

Differences in electrocardiographic parameters between symptomatic and asymptomatic BrS patients

\begin{tabular}{lccc}
\hline & $\begin{array}{c}\text { Symptomatic } \\
\text { cases (n=35) }\end{array}$ & $\begin{array}{c}\text { Asymptomatic } \\
\text { cases (n=101) }\end{array}$ & p value \\
\hline Age (years) & $48 \pm 15$ & $46 \pm 15$ & 0.53 \\
Male & $23(66 \%)$ & $67(66 \%)$ & 0.23 \\
Age of diagnosis (years) & $42 \pm 13$ & $42 \pm 15$ & 0.86 \\
QRS duration (ms) & $113 \pm 17$ & $117 \pm 17$ & 0.26 \\
QRS peak lead II (mm) & $8 \pm 3$ & $12 \pm 4$ & $<0.001$ \\
QRS peak lead V6 (mm) & $8 \pm 3$ & $11 \pm 3$ & $<0.001$ \\
QRS trough lead V2 (mm) & $9 \pm 4$ & $12 \pm 4$ & 0.001 \\
QRS vector magnitude (mV) & $1.24 \pm 0.35$ & $1.78 \pm 0.42$ & $<0.001$ \\
Positive RVOT signs & $19(54 \%)$ & $6(6 \%)$ & $<0.001$ \\
Positive late potentials & $10(29 \%)$ & $46(46 \%)$ & 0.07 \\
\hline
\end{tabular}

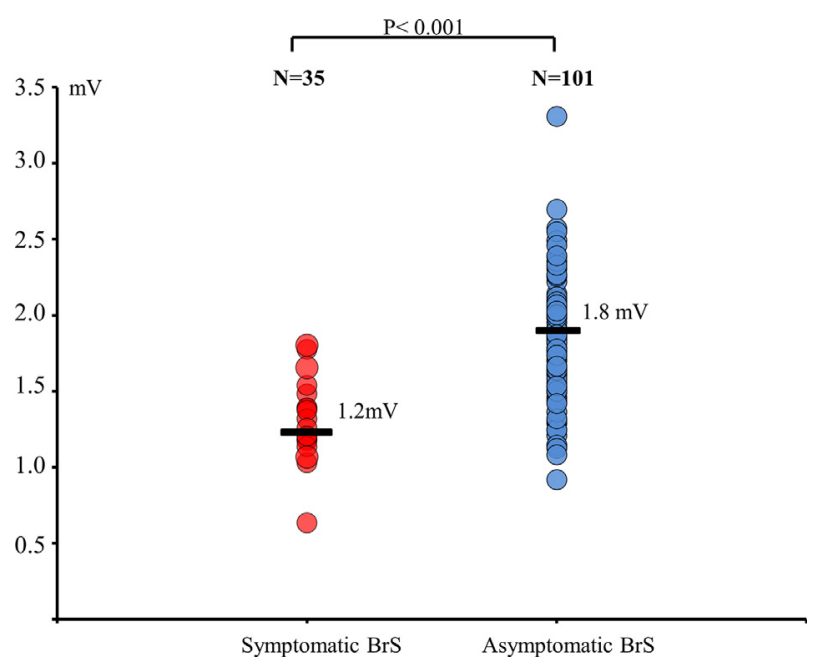

Figure 2. Scatterplot demonstrating the QRSvm of symptomatic and asymptomatic $\mathrm{BrS}$ patients.

\section{Discussion}

In this study, we demonstrate the significance of QRSvm and positive RVOT signs as predictors for VTA in BrS. Patients with QRSmv lower than 1.55 were 4 times more likely to develop VTA. Moreover, patients with 3 or more positive RVOT signs have a threefold higher risk of VTA.

$\mathrm{BrS}$ is an autosomal dominant channelopathy responsible for $4 \%$ to $12 \%$ of all sudden cardiac deaths. The highest prevalence of $\mathrm{BrS}$ is among Asians. ${ }^{17} \mathrm{BrS}$ is more prevalent among men and they also have worse prognosis compared with women. ${ }^{18} \mathrm{BrS}$ patients are either diagnosed incidentally or present with a wide range of symptoms such syncope, seizures, or VTA. Risk stratification of $\mathrm{BrS}$ patients is the most challenging part in the management of this channelopathy. Many investigators reported on to testing of electrocardiographic markers to identify high-risk $\mathrm{BrS}$ patients. ${ }^{4,19-21}$ These markers include f-QRS and QRS duration in V2. ${ }^{22}$ However, we still do not have clear noninvasive predictors for VTA, specifically for asymptomatic

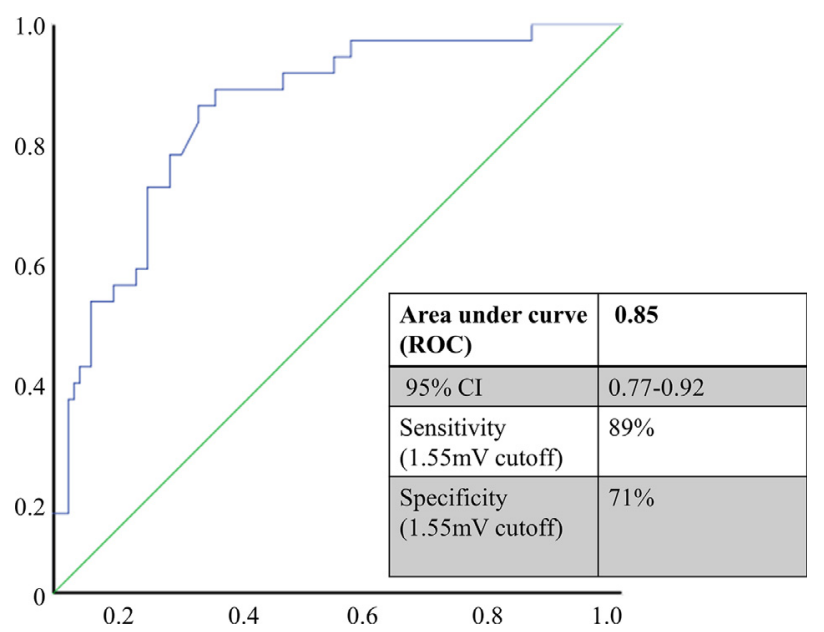

Figure 3. Receiver operator characteristic curve demonstrating the sensitivity and specificity of QRSmv parameter. 
patients. QRS duration showed a promising prognostic value in some studies but it did not show value in large registries. ${ }^{6,7}$ In addition, other diagnostic and prognostic parameters than QRS duration and ECG-derived vectorcardiographic parameters such as spatial QRS-T angle have been evaluated for stratifying high-risk patients in different populations. Borleffs et $\mathrm{al}^{9}$ showed that a wide QRS-T angle is a strong predictor for appropriate ICD shocks in patients with ischemic heart disease. In another study, a wide spatial QRS-T angle is also associated with diabetes type 2, impaired glycemic control, and decreased left ventricular function. ${ }^{8}$ Kardys et $\mathrm{al}^{23}$ showed that spatial QRS-T angle is a strong predictor of cardiac mortality in the elderly.

Quantifying the scattering of electric waves by calculating the QRSvm showed a prognostic value in recent studies. Cortez et $\mathrm{al}^{11}$ tested the significance of QRSvm as a predictor of VTA in TOF patients who underwent pulmonary valve replacement with a negative predictive value of $95 \%$ and OR of 34 (95\% CI 3.9 to 293.3). They also showed that QRSvm can predict VTA inducibility in TOF patients with area under receiver operator characteristic curve of 0.75 and relative risk of 2.59 (95\% CI 1.48 to 4.71$).{ }^{12}$ Nagase et $\mathrm{al}^{24}$ showed that low voltage type $1 \mathrm{ECG}$ of $\mathrm{BrS}$ is highly and independently associated with VTA. The recent subxiphoid epicardial mapping approach revealed that the RVOT of symptomatic BrS patients showed areas of low voltage and delayed fragmented potentials and ablation of the anterior aspect of RVOT epicardium normalized $\mathrm{BrS}$ pattern in most of these patients. ${ }^{25,26}$ In line with these results, our study not only supports that low voltage is associated with high risk of VTA in BrS, but also introduced a noninvasive ECG-derived parameter to identify these highrisk patients.

Positive RVOT conduction delay signs were tested by our group in 2 previous studies. ${ }^{13,14}$ In this study, we combined all variables into 1 and still showed an independent predictor for VTA with odds ratio of 2.6 (95\% CI 1.4 to $4.9, \mathrm{p}=0.001)$ and area under receiver operator characteristic of 0.74 (95\% CI 0.633 to 0.85 ).

In conclusion, QRSvm and positive RVOT conduction delay signs can be beneficial noninvasive independent predictors of VTA in BrS patients. However, our observations need to be further evaluated in a multicenter study with larger number of $\mathrm{BrS}$ patients.

\section{Disclosures}

This research did not receive any specific grant from funding agencies in the public, commercial, or non-profit sectors.

1. Brugada P, Brugada J. Right bundle branch block, persistent ST segment elevation and sudden cardiac death: a distinct clinical and electrocardiographic syndrome. J Am Coll Cardiol 1992;20:1391-1396.

2. Bayes de Luna A, Brugada J, Baranchuk A, Borggrefe M, Breithardt G, Goldwasser D, Lambiase P, Riera AP, Garcia-Niebla J, Pastore C, Oreto G, McKenna W, Zareba W, Brugada R, Brugada P. Current electrocardiographic criteria for diagnosis of Brugada pattern: a consensus report. $J$ Electrocardiol 2012;45:433-442.

3. Morita H, Kusano KF, Miura D, Nagase S, Nakamura K, Morita ST, Ohe T, Zipes DP, Wu J. Fragmented QRS as a marker of conduction abnormality and a predictor of prognosis of Brugada syndrome. Circulation 2008;118:1697-1704.

4. Huang Z, Patel C, Li W, Xie Q, Wu R, Zhang L, Tang R, Wan X, Ma Y, Zhen W, Gao L, Yan GX. Role of signal-averaged electrocardiograms in arrhythmic risk stratification of patients with Brugada syndrome: a prospective study. Heart Rhythm 2009;6:1156-1162.

5. Tokioka K, Kusano KF, Morita H, Miura D, Nishii N, Nagase S, Nakamura K, Kohno K, Ito H, Ohe T. Electrocardiographic parameters and fatal arrhythmic events in patients with Brugada syndrome: combination of depolarization and repolarization abnormalities. J Am Coll Cardiol 2014;63:2131-2138.

6. Maury P, Rollin A, Sacher F, Gourraud J-B, Raczka F, Pasquié J-L, Duparc A, Mondoly P, Cardin C, Delay M, Derval N, Chatel S, Bongard V, Sadron M, Denis A, Davy J-M, Hocini M, Jaï P, Jesel L, Haïssaguerre M, Probst V. Prevalence and prognostic role of various conduction disturbances in patients with the Brugada syndrome. Am J Cardiol 2013;112:1384-1389.

7. Priori SG, Gasparini M, Napolitano C, Della Bella P, Ottonelli AG, Sassone B, Giordano U, Pappone C, Mascioli G, Rossetti G, De Nardis $\mathrm{R}$, Colombo M. Risk stratification in Brugada syndrome: results of the PRELUDE (PRogrammed ELectrical stimUlation preDictive valuE) Registry. J Am Coll Cardiol 2012;59:37-45.

8. Voulgari C, Tentolouris N, Moyssakis I, Dilaveris P, Gialafos E, Papadogiannis D, Votteas V, Cokkinos DV, Stefanadis C, Katsilambros N. Spatial QRS-T angle: association with diabetes and left ventricular performance. Eur J Clin Invest 2006:36:608-613.

9. Borleffs CJ, Scherptong RW, Man SC, van Welsenes GH, Bax JJ, van Erven L, Swenne CA, Schalij MJ. Predicting ventricular arrhythmias in patients with ischemic heart disease: clinical application of the ECGderived QRS-T angle. Circ Arrhythm Electrophysiol 2009;2:548-554.

10. de Torbal A, Kors JA, van Herpen G, Meij S, Nelwan S, Simoons ML, Boersma E. The electrical T-axis and the spatial QRS-T angle are independent predictors of long-term mortality in patients admitted with acute ischemic chest pain. Cardiology 2004;101:199-207.

11. Cortez D, Barham W, Ruckdeschel E, Sharma N, McCanta AC, von Alvensleben J, Sauer WH, Collins KK, Kay J, Patel S, Nguyen DT. Noninvasive predictors of ventricular arrhythmias in patients with tetralogy of Fallot undergoing pulmonary valve replacement. JACC Clin Electrophysiol 2017:3:162-170.

12. Cortez D, Ruckdeschel E, McCanta AC, Collins K, Sauer W, Kay J, Nguyen D. Vectorcardiographic predictors of ventricular arrhythmia inducibility in patients with tetralogy of Fallot. J Electrocardiol 2015; 48:141-144

13. Ragab AAY, Houck CA, van der Does L, Lanters EAH, Burghouwt DE, Muskens A, de Groot NMS. Usefulness of the R-wave sign as a predictor for ventricular tachyarrhythmia in patients with Brugada syndrome. Am J Cardiol 2017;120:428-434.

14. Ragab AAY, Houck CA, van der Does L, Lanters EAH, Muskens A, de Groot NMS. Prediction of ventricular tachyarrhythmia in Brugada syndrome by right ventricular outflow tract conduction delay signs. $J$ Cardiovasc Electrophysiol 2018;29:998-1003.

15. Tzou WS, Zado ES, Lin D, Callans DJ, Dixit S, Cooper JM, Bala R, Garcia F, Hutchinson MD, Riley MP, Deo R, Gerstenfeld EP, Marchlinski FE. Sinus rhythm ECG criteria associated with basallateral ventricular tachycardia substrate in patients with nonischemic cardiomyopathy. J Cardiovasc Electrophysiol 2011;22:1351-1358.

16. Kors JA, van Herpen G, Sittig AC, van Bemmel JH. Reconstruction of the Frank vectorcardiogram from standard electrocardiographic leads: diagnostic comparison of different methods. Eur Heart J 1990;11:1083-1092.

17. Quan X-Q, Li S, Liu R, Zheng K, Wu X-F, Tang Q. A meta-analytic review of prevalence for Brugada ECG patterns and the risk for death. Medicine 2016:95:e5643-e5643.

18. Benito B, Sarkozy A, Mont L, Henkens S, Berruezo A, Tamborero D, Arzamendi D, Berne P, Brugada R, Brugada P, Brugada J. Gender differences in clinical manifestations of Brugada syndrome. J Am Coll Cardiol 2008:52:1567-1573.

19. Junttila MJ, Brugada P, Hong K, Lizotte E, M DEZ, Sarkozy A, Brugada J, Benito B, Perkiomaki JS, Makikallio TH, Huikuri HV, Brugada R. Differences in 12-lead electrocardiogram between symptomatic and asymptomatic Brugada syndrome patients. J Cardiovasc Electrophysiol 2008; 19:380-383.

20. Coronel R, Casini S, Koopmann TT, Wilms-Schopman FJ, Verkerk AO, de Groot JR, Bhuiyan Z, Bezzina CR, Veldkamp MW, Linnenbank AC, van der Wal AC, Tan HL, Brugada P, Wilde AA, de Bakker JM. Right 
ventricular fibrosis and conduction delay in a patient with clinical signs of Brugada syndrome: a combined electrophysiological, genetic, histopathologic, and computational study. Circulation 2005;112:2769-2777.

21. Nagase S, Kusano KF, Morita H, Fujimoto Y, Kakishita M, Nakamura $\mathrm{K}$, Emori T, Matsubara H, Ohe T. Epicardial electrogram of the right ventricular outflow tract in patients with the Brugada syndrome: using the epicardial lead. J Am Coll Cardiol 2002;39:1992-1995.

22. Ohkubo K, Watanabe I, Okumura Y, Ashino S, Kofune M, Nagashima K, Kofune T, Nakai T, Kunimoto S, Kasamaki Y, Hirayama A. Prolonged QRS duration in lead V2 and risk of life-threatening ventricular arrhythmia in patients with Brugada syndrome. Int Heart J 2011;52:98-102.

23. Kardys I, Kors J, van der Kuip D, Witteman J, Hofman A. Spatial QRS-T angle predicts cardiac death in a general population. Eur Heart $J$ 2003;24:1357-1364.
24. Nagase S, Kamakura T, Kataoka N, Wada M, Yamagata K, Ishibashi K, Inoue YY, Miyamoto K, Noda T, Aiba T, Izumi C, Noguchi T, Yasuda S, Shimizu W, Kamakura S, Kusano K. Low-voltage type 1 ECG is associated with fatal ventricular tachyarrhythmia in Brugada syndrome. J Am Heart Assoc 2018;7:e009713.

25. Josep B, Carlo P, Antonio B, Gabriele V, Francesco M, Giuseppe C, Luigi G, Vincenzo S. Brugada syndrome phenotype elimination by epicardial substrate ablation. Circ Arrhythm Electrophysiol 2015;8:1373-1381.

26. Koonlawee N, Gumpanart V, Pakorn C, Lertlak C, Aekarach A, Kriengkrai J, Khanchit L, Kiertijai B, Tachapong N. Prevention of ventricular fibrillation episodes in brugada syndrome by catheter ablation over the anterior right ventricular outflow tract epicardium. Circulation 2011;123:1270-1279. 